\title{
'|||||||||||||||||||||||||||||||||||||||||||||||||||||||||||||||||||.
}

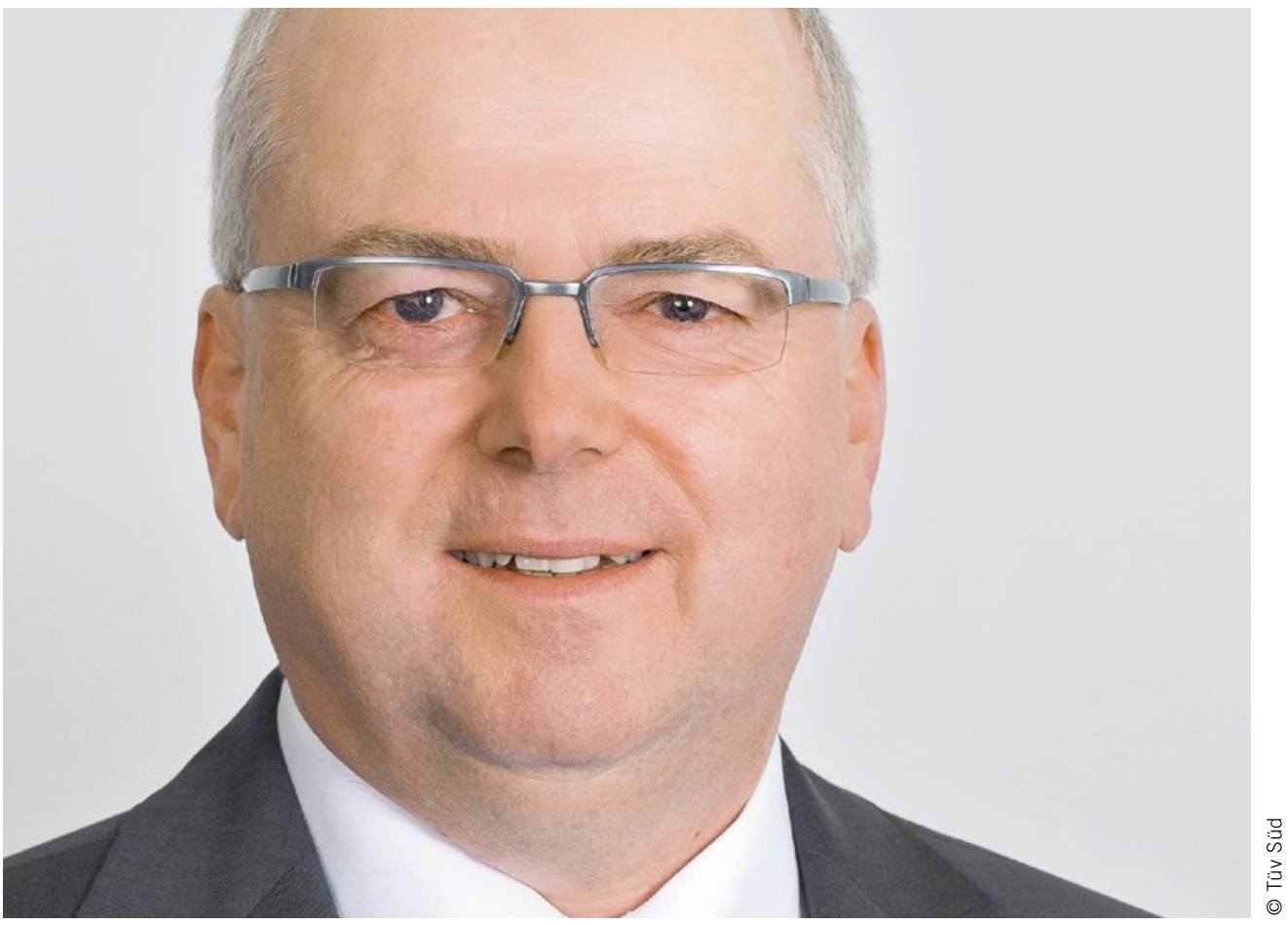

Dipl.-Ing. Klemens Schmiederer Mitglied des Vorstands, Tüv Süd

\section{Rasante Assistenzsysteme}

Die zwei großen Erfindungen des letzten Jahrhunderts verschmelzen: Digitale Welt und das mechanische Automobil werden eins. Technologische Grundlage dafür ist die rasante Entwicklung der Fahrerassistenzsysteme. Nachtsicht, Objektund Fahrspurerkennung, Abstandsmessung, Nahbereichsüberwachung und viele andere Hilfssysteme: Autofahren ist schon heute assistiertes Fahren.

Der nächste Schritt heißt automatisiertes Fahren - für Ingenieure eine natürliche Evolution. Für den Autofahrer aber eher eine Revolution. Schließlich gibt er Macht und Kontrolle an die Bordcomputer ab. Trotzdem ist das Interesse gewaltig, denn die Vorteile liegen auf der Hand: mehr Sicherheit durch kürzere Reaktionszeiten, höhere Effizienz durch vorausschauendes Fahren, mehr Mobilität durch Koordination in Stoßzeiten und mehr Komfort durch die Entlastung des Fahrers.

Damit automatisiertes Fahren den Durchbruch schafft, muss das Vertrauen der Autofahrer - vor allem in die Sicherheit hergestellt werden. Einer der wichtigsten Eckpfeiler dafür ist die Hauptuntersuchung (HU). Sie stellt sicher, dass alle sicherheitsrelevanten Systeme ein ganzes Autoleben lang einwandfrei funktionieren. Die HU muss dazu ständig an den rasanten technischen Fortschritt angepasst werden. Ein entscheidender Schritt war der HU-Adapter. Er erkennt Störungen und Ausfälle von Sensoren und Steuergeräten. Sicherheit bedeutet im Zusammenhang mit automatisiertem Fahren aber nicht nur funktio- nale Sicherheit, sondern auch Schutz vor Hackerangriffen. Verschiedene Schutzmechanismen sorgen deshalb dafür, dass sicherheitsrelevante Systeme in der Fahrzeugelektronik von anderen, wie beispielsweise der Navigation oder dem Infotainment, strikt getrennt sind. Lenken, Bremsen und Gas geben - also die Fahrfunktionen - sind so vor Angriffen und Manipulationen von außen geschützt.

Neben Sicherheit und Vertrauen braucht es zudem einheitliche Regeln. Welche gewaltigen Aufgaben da noch vor uns liegen, zeigt eine Frage aus dem Politikbrief des VDA zu Beginn des Jahres: „Welche Sprache spricht die Ampel der Zukunft, damit wirklich alle Autos sie verstehen?" Hier müssen klare rechtliche Rahmenbedingungen geschaffen und umgesetzt werden. An der Schnittstelle dazwischen sorgt ein neutraler Dritter für Transparenz - das gilt für die Entwicklung von Fahrzeugen, Infrastruktur und Datenwelt genauso wie für den Betrieb.

Tüv-Süd-Experten aus den verschiedensten Fachbereichen unterstützen als unabhängiger Dritter den gesamten Entwicklungsprozess von Fahrzeugen und Systemen. Dafür halten wir Benennungen und Akkreditierungen für mehr als 400 Vorschriften - weltweit. Das Dienstleistungsspektrum reicht von kompletten Sicherheitskonzepten und Risikoanalysen für gesamte Fahrzeugkonzepte und -systeme bis hin zu Rollwiderstandsmessungen, um den Verbrauch zu optimieren. 